Volume: 14 Issue: 3 Year: 2017

\title{
The relationship between reactive and proactive Aggression and emotional and behavioral difficulties: Criterion validity of the Reactive-Proactive Aggression Questionnaire (RPQ) among preadolescents
}

\author{
Aslı Uz Baş ${ }^{1}$ \\ İrfan Yurdabakan ${ }^{2}$
}

\begin{abstract}
The present study aimed to assess the criterion validity of the Reactive-Proactive Aggression Questionnaire (RPQ) in a Turkish sample of preadolescents. Participants consisted of 379 middle school students (190 boys and 189 girls) aged 11 to 15 years. In this study, the Strengths and Difficulties Questionnaire (SDQ) was used as the criterion instrument. Findings from stepwise regression analysis revealed that conduct problems were the strongest predictor of both reactive and proactive aggression. Additionally, reactive aggression was uniquely predicted by emotional symptoms and hyperactivity, whereas proactive aggression was uniquely predicted by prosocial behavior. Our results indicate that the RPQ has acceptable criterion validity for use in Turkish preadolescents.
\end{abstract}

Keywords: Criterion validity; the Reactive-Proactive Aggression Questionnaire; preadolescents; the Strengths and Difficulties Questionnaire

\section{Introduction}

Aggression among children and adolescents is a serious problem in many countries across the world. Card (2013) stated that aggressive children face several short- and long-term negative consequences, and these negative consequences often worsen over time, leading to delinquency, substance use, and school dropout during adolescence. Moreover, aggressive behavior in childhood can lead to negative outcomes during adulthood including criminal behavior, poor marital relations, and unemployment. In addressing aggressive behaviors in schools it is necessary to understand the different forms of aggression. Aggressive behaviors are divided into two categories in terms of underlying functions: Reactive aggression and proactive aggression (Dodge \& Coie, 1987). In order to intervene effectively these problem behaviors, educators and school counselors need to know the function that underlies aggressive behaviors.

\section{Reactive Aggression Versus Proactive Aggression}

Reactive aggression is a defensive, retaliatory response to a perceived provocation from a peer and includes displaying anger (Hubbard, Dodge, Cillessen, Coie, \& Schwartz, 2001). Its major goal is to react to the anger-frustration stimulus and hurt the perpetrator of the provocation or the threat. Reactive aggression might be used as a synonym for "defensive", "angry", "hot-blooded",

\footnotetext{
1 Assoc. Prof. Dr., Dokuz Eylül University, Buca Faculty of Education, Department of Educational Sciences, asliuzbas@gmail.com

2 Assoc. Prof. Dr., Dokuz Eylül University, Buca Faculty of Education, Department of Educational Sciences, irfan.ybakan@gmail.com
} 
Uz Baş, A., \& Yurdabakan, İ. (2017). The relationship between reactive and proactive Aggression and emotional and behavioral difficulties: Criterion validity of the Reactive-Proactive Aggression Questionnaire (RPQ) among preadolescents. Journal of Human Sciences, 14(3), 2553-2564. doi:10.14687/jhs.v14i3.4494

"impulsive", "emotional", and "retaliatory" aggression (Vitaro, Brendgen, \& Barker, 2006). Examples of reactive aggression might include instances when a child slaps or kicks in retaliation of an accidental push or touch from another, or if a child accidentally trips over an object and then shoves the closest available person (Rathert, 2009). Reactive aggression has its theoretical roots in the frustration-aggression model (Berkowitz, 1989). According to this framework, frustrations are aversive events and generate aggressive inclinations only to the extent that they produce negative affect. An unexpected failure to obtain a desired goal is more unpleasant than an expected failure, and it is the greater displeasure in the former case that gives rise to the stronger provocation to aggression.

Proactive aggression is an unprovoked, deliberate, goal-directed behavior used to impress or coerce a peer (Hubbard et al., 2001). Synonyms for proactive aggression are "offensive", "instrumental", and "coldblooded" aggression (Vitaro, Brendgen, \& Barker, 2006). A child who hits a peer in order to take their snack or a child who threatens physical harm to get their way would be the examples of proactive aggression (Rathert, 2009). The theoretical roots of proactive aggression can be found in social learning theory. Social learning theory posits that people acquire aggressive responses the same way they acquire other complex forms of social behavior. According to social learning theory aggressive behavior is acquired via observational learning processes (Anderson \& Bushman, 2002).

The reactive-proactive dichotomy has been supported by several studies (Fossati et al., 2009; Fung, Raine, \& Gao, 2009; Poulin \& Boivin, 2000; Raine et al., 2006; Vitaro et al., 2006). Reactive and proactive aggression appear to be related to differential social information-processing patterns (Crick \& Dodge, 1996; Poulin \& Boivin, 1999), cognitive and emotional characteristics (Marsee \& Frick, 2007; Pulkkinen, 1996; Vitaro, Gendreau, Tremblay, \& Oligny, 1998) and developmental features (Crick \& Dodge, 1996). Day, Bream, and Paul (1992) found that there are significant behavioral differences between proactively and reactively aggressive school-aged boys in terms of teacher-ratings. Reactively aggressive boys were less able to handle peer pressure than were nonaggressive boys. They performed more poorly at school and had more internalized symptoms. Reactively aggressive children display histories of physical abuse and early onset of problems (Dodge et al., 1997). They interpret others' ambiguous provocations as hostile more readily than proactively or reactively and proactively aggressive children. They also demonstrate more problemsolving deficits in difficult social situations. (Crick \& Dodge, 1996; Dodge \& Coie, 1987) Reactively aggressive children also tend to demonstrate attention problems and adjustment problems in peer (Dodge \& Coie, 1987). Conversely, proactively aggressive boys did not have more school problems and did not manifest more internalized symptoms than nonaggressive boys. Proactively aggressive children demonstrate a processing pattern of anticipating relatively positive outcomes for aggression (Dodge et al., 1997). They are likely to view aggression as an effective and appropriate means for obtaining social goals. Proactive aggression can lead to externalizing problems such as delinquency and disruptive behaviors, however reactive aggression does not (Pulkkinen, 1996; Vitaro et al., 1998). Similarly, Raine and colleagues (2006) claimed that proactive aggression, but not reactive aggression would be most strongly associated with delinquency, serious and violent criminal acts, initiation of fights, and the use of strong-arm tactics in childhood. Proactive aggression is also a unique predictor of delinquency-related violence (Brendgen, Vitaro, Tremblay \& Lavoie, 2001). In a recent study conducted by Euler, Steinlin and Stadler (2017), it was found that cognitive and affective empathy were significantly associated with proactive aggression, but not with reactive aggression. Reactive and proactive aggression are also differentiated by parental attitudes. McAuliffe, Hubbard, Rubin, Morrow and Dearing (2007) suggests that reactive aggression grows out of earlier physical abuse and harsh parenting, whereas proactive aggression results from earlier exposure to aggressive models. 
Uz Baş, A., \& Yurdabakan, İ. (2017). The relationship between reactive and proactive Aggression and emotional and behavioral difficulties: Criterion validity of the Reactive-Proactive Aggression Questionnaire (RPQ) among preadolescents. Journal of Human Sciences, 14(3), 2553-2564. doi:10.14687/jhs.v14i3.4494

Differentiating these different forms of aggression is important to obtain a clearer understanding of the etiology of aggression (Raine et al., 2006). Knowing the function that underlies aggressive behavior is crucial additional information because it teaches us why individuals engage in aggressive behavior (Little, Brauner, Jones, Nock, \& Hawley, 2003). In addition, dissimilar aggression types may differentially respond to specific therapeutic interventions (Connor, Anderson, Steingard, Cunningham, \& Melloni, 2004). Knowing why people become aggressive, set light to possibilities to intervene (Polman, 2008).

\section{Measuring Reactive and Proactive Aggression}

Various measures have been developed to examine the distinction between reactive aggression and proactive aggression. One of the most commonly used questionnaire is the TeacherRating Scale developed by Dodge and Coie (1987). Numerous studies have been used the measure to determine reactive and proactive aggression in children (e.g., Connor, Steingard, Anderson, \& Melloni, 2003; Crick \& Dodge, 1996; Hubbard et al., 2002). Some researchers have used the ParentRating Scale for Reactive and Proactive Aggression (PRPA; Kempes et al., 2005) and Revised Parent-Rating Scale for Reactive and Proactive Aggression (R-PRPA; Brown, Atkins, Osborne, \& Milmanow, 1996) to assess reactive and proactive aggression. Besides these questionnaires, reactive aggression and proactive aggression have been assessed by using behavioral observations of playgroup interactions in some studies (e.g., Hubbard et al., 2001; Kempes et al., 2010).

Recently, a self-report measure was developed to specifically evaluate these two forms of aggressive behavior (Raine et al., 2006). The Reactive-Proactive Aggression Questionnaire (RPQ) consists of 23 behavioral items and is appropriate for use with children, adolescents, and young adults. Raine et al. reported that intrinsic motivation for reactive and proactive aggression is important, therefore self-report measures of proactive-reactive aggression would have a potentially important advantage over more objective teacher rating or observational measures. Recent studies of cross-cultural generalizability of the scale suggest that the RPQ can be operationalized successfully in different countries (Ang, Huan, Li \& Chan, 2016; Fossati et al., 2009; Fung et al., 2009; Pechorro et al., 2015; Uz Baş \& Yurdabakan, 2012). A variety of studies, across a number of diverse samples have further contributed to the score validity of the RPQ. For example, Raine and colleagues (2006) reported that proactive aggression was uniquely characterized at age 7 by delinquency, poor school motivation, poor peer relationships, psychosocial adversity, and hyperactivity, and at age 16 by a psychopathic personality, blunted affect, delinquency, and serious violent offending. However, reactive aggression was uniquely characterized at age 16 by impulsivity, hostility, social anxiety, lack of close friends, unusual perceptual experiences, and ideas of reference. Subsequent research has also provided support of the validity of the RPQ. Fossati and colleagues (2009) examined the psychometric properties of the RPQ in a sample of nonreferred Italian high school students. They found that the proactive aggression showed a unique association with bullying behaviors while the reactive aggression was unrelated after accounting for the shared variance of the proactive scale. Bozsik and colleagues (2013) investigated the relationship between reactive/proactive aggression, callous/unemotional traits and behavioural problems in Hungarian adolescents. The researchers found that in both genders, reactive aggression was specifically associated with emotional and peer-related problems. They also reported that the strongest positive correlation was observed between self-reported conduct symptoms and both types of aggressive behavior. Pechorro and colleagues (2016) tested the validity of the RPQ among a Portuguese sample of incarcerated juvenile delinquents. They found that the RPQ total and the reactive dimension revealed negative significant correlations with the self-esteem scores, while the proactive dimension showed a non-significant correlation. It was also found that there were unique associations between the proactive dimension and measures of antisocial behavior. Ang and colleagues (2016) investigated the factor structure and invariance of the RPQ in a large sample of young adolescents in Singapore. They reported that both reactive and proactive aggression were 
Uz Baş, A., \& Yurdabakan, İ. (2017). The relationship between reactive and proactive Aggression and emotional and behavioral difficulties: Criterion validity of the Reactive-Proactive Aggression Questionnaire (RPQ) among preadolescents. Journal of Human Sciences, 14(3), 2553-2564. doi:10.14687/jhs.v14i3.4494

found to be positively and significantly related to delinquency and narcissism, whereas proactive aggression rather than reactive aggression showed relatively stronger associations with delinquency and narcissism. Colins (2016) assessed reactive and proactive aggression in detained adolescents. The findings showed that reactive aggression was positively related to symptoms of depression and anxiety, suicide ideations, social problems, alcohol and drug use, psychopathic traits and threats, but differently from prosocial behavior, violent offenses, theft, vandalism and drug offenses. Proactive aggression was not significantly associated with symptoms of depression and anxiety, suicide ideations, social problems, but negatively related to prosocial behavior, and positively related to all the other outcomes.

\section{Purpose}

The present study assessed the criterion validity of the RPQ in a Turkish sample of schoolgoing preadolescents. In this study, we used the Strengths and Difficulties Questionnaire (SDQ) as the criterion instrument. Based on prior research, we hypothesized that both reactive and proactive aggression would be positively and significantly associated with conduct problems, emotional symptoms, hyperactivity and peer problems. Additionally, we hypothesized that both reactive and proactive aggression would be negatively and significantly associated with prosocial behavior. Empirical findings have shown that conduct problems are more closely associated with proactive rather than reactive aggression (e.g., Bozsik et al., 2013). Given these findings, we also hypothesized that relatively stronger relationship for proactive than reactive aggression would be found in relation to conduct problems. Theoretical findings have indicated that reactive aggression is characterized as impulsive, defensive and emotional responses. Unlike reactive aggression, proactive aggression does not characteristically occur as an emotion-laden, defensive response to immediate threat (e.g., McAdams, 2002). Thus, we hypothesized that relatively stronger relationship for reactive than proactive aggression would be found in relation to emotional difficulties and hyperactivity. We expect to provide further evidence for criterion validity of the RPQ and to provide further support the reactive-proactive aggression dichotomy among a sample of Turkish preadolescents. We also explored gender and grade level differences in reactive and proactive aggression. Based on previous research (Fung et al., 2009; Salmivalli \& Nieminen, 2002; Uz Baş \& Yurdabakan, 2012), we hypothesized both reactive and proactive scores would be higher for boys than for girls. Next, we hypothesized that reactive and proactive aggression would increase with age.

\section{Method}

\section{Participants}

The sample consisted of 379 Turkish students, 190 males (50.1\%) and 189 females (49.9\%). Participants were attending three public middle schools in Izmir, Turkey. Participants' ages ranged 11 to $15(\mathrm{M}=13.3, \mathrm{SD}=.94)$. One hundred and fourteen of them were sixth graders, 138 of them were seventh graders, and 127 of them were eighth graders.

\section{Measures}

The Reactive-Proactive Aggression Questionnaire (The RPQ): The RPQ is a self-report questionnaire designed to distinguish between reactive and proactive aggression. The RPQ is composed of 23 items and 2 subscales. A total of 11 items assess reactive aggression (e.g., "Reacted angrily when provoked by others") and 12 items proactive aggression (e.g., "Hurt others to win a game"). The items were rated on a 3-point scale, with the following response options: $0=$ never, 1 $=$ sometimes, and $2=$ often. For each subscale and the total scale, higher scores indicate higher levels of aggression. The Cronbach's alpha coefficients have previously been reported as .84, .86, and .90 for reactive aggression, proactive aggression, and total aggression, respectively (Raine et al., 
Uz Baş, A., \& Yurdabakan, İ. (2017). The relationship between reactive and proactive Aggression and emotional and behavioral difficulties: Criterion validity of the Reactive-Proactive Aggression Questionnaire (RPQ) among preadolescents. Journal of Human Sciences, 14(3), 2553-2564. doi:10.14687/jhs.v14i3.4494

2006). The scale is appropriate for use with children, late adolescents and young adults. Uz Baş and Yurdabakan (2012) were adapted the scale into Turkish in a study with Turkish children aged 9 to 14. Findings from the confirmatory factor analysis provided evidence for the two-factor reactiveproactive model. The relative chi-square difference test indicated a significantly better fit for the two factor model over the one-factor model, $\Delta \chi^{2}=465.39, \mathrm{df}=1, \mathrm{p}<.01$. The two-factor model provided a satisfactory fit, GFI $=0.95$, AGFI $=0.94$, CFI $=0.97$, SRMR $=0.04$, RMSEA $=0.04$, and $\chi 2(229, \mathrm{n}=1.081)=676.61, \mathrm{p}=.05, \chi^{2} / \mathrm{df}=2.95$. Reactive and Proactive Aggression scales and Total Aggression scale showed high internal consistency. The Cronbach's alpha coefficients were found $.77, .79$, and .84 for the Proactive scale, the Reactive scale, and the Total scale.

The Strengths and Difficulties Questionnaire (the SDQ): The SDQ is a measure of mental health problems in children aged 4-17. The scale can be administered to parents, teachers and to children aged 11 or over. The 20 items relating to emotional symptoms, conduct problems, hyperactivity and peer problems are summed to create a total difficulty score. The questionnaire was developed by Goodman and Goodman (2009) and adapted into Turkish by Güvenir and colleagues (2008) and Dursun, Güvenir and Özbek (2010). The Cronbach's alpha coefficients were found .84 for the Total Difficulties, .73 for the Emotional Symptoms, .65 for the Conduct Problems, .80 for the Hyperactivity, .37 for the Peer Problems, and .73 for the Prosocial Behavior.

\section{Procedure}

The study was conducted in the 2013-2014 academic year. School administration approval was obtained for the study. Students were informed that the researchers of the present study were interested in better understanding aggressive behaviors and their correlates among preadolescents. They were also told that this is a voluntary study and the data from the study would only serve scientific purposes. All of the students accepted to participate in the study. Questionnaires were distributed to the students in their classrooms. It took 15 to $20 \mathrm{~min}$ to fill out the scales. Data collection was undertaken by the authors.

\section{Data Analyses}

All analyses were performed using the Statistical Package for Social Sciences (SPSS, version 16.0). During data analysis, descriptive statistics for each of the variables were calculated. The relationship between the RPQ scores and the SDQ scores were examined using Pearson correlations. Finally, multiple regression analysis (stepwise method) was used to assess the criterion validity of the RPQ, using the SDQ as criterion instrument.

\section{Results}

\section{Descriptive Analyses}

Means, standard deviations, the range, skewness and kurtosis for the RPSQ and the SDQ scores are provided in Table 1 . Reactive aggression was considerably more prevalent than proactive aggression (paired $\mathrm{t}=28.64 \mathrm{df}=.378, \mathrm{p}<.001$ ). The effect size was medium (Cohen's $\mathrm{d}=0.30$ ), indicating a moderate practical significance (Cohen, Manion, \& Morrison, 2007). 
Uz Baş, A., \& Yurdabakan, İ. (2017). The relationship between reactive and proactive Aggression and emotional and behavioral difficulties: Criterion validity of the Reactive-Proactive Aggression Questionnaire (RPQ) among preadolescents. Journal of Human Sciences, 14(3), 2553-2564. doi:10.14687/jhs.v14i3.4494

Table 1. Descriptive Statistics

\begin{tabular}{lcccccc}
\hline Study Variable & $M$ & $S D$ & Skewness & Kurtosis & $n$ & Min. to Max. \\
\hline Reactive Aggression & 7.35 & 4.231 & .400 & -.360 & 379 & $0-21$ \\
Proactive Aggression & 1.82 & 2.661 & 2.117 & 4.954 & 379 & $0-15$ \\
Total Aggression & 9.18 & 5.986 & .912 & .968 & 379 & 032 \\
Emotional Symptoms & 2.75 & 2.089 & .597 & -.195 & 379 & $0-9.00$ \\
Conduct Problems & 2.11 & 1.590 & .985 & 1.225 & 379 & $0-9.00$ \\
Hyperactivity & 3.87 & 1.972 & .006 & -.358 & 379 & $0-10.00$ \\
Peer Problems & 2.85 & 1.790 & .524 & -.001 & 379 & $0-9.00$ \\
Prococial Behavior & 8.21 & 1.794 & -.901 & .186 & 379 & $1.00-10.00$ \\
Total Difficulties & 11,57 & 5,149 & .350 & -.202 & 379 & $0-27.00$ \\
\hline
\end{tabular}

\section{Gender and Grade Differences}

To investigate gender and age differences in the the RPQ subscores, a 2 (gender) $\times 3$ (grade) univariate analysis of variance was performed. With regard to the Reactive Aggression scores, the results revealed a nonsignificant main effect for gender, $\mathrm{F}(1,373)=2.19, \mathrm{p}>.05$. A significant main effect for grade was observed, $\mathrm{F}(2,373)=29.94, \mathrm{p}<.001$, with reactive aggression generally increasing with increasing grade. Post hoc analyses (Least Significant Difference test) showed that sixth grade students had lower reactive aggression than seventh graders $(\mathrm{p}<.001)$, and eighth graders $(\mathrm{p}<.001)$. The effect size $\left(\eta^{2}\right)$ was 0.14 , indicating modest effect. A significant Gender $\times$ Grade interaction was also observed, $\mathrm{F}(2,373)=6.60, \mathrm{p}<.001$, indicating that genders differed with respect to the development of reactive aggression. The effect size $\left(\eta^{2}\right)$ was 0.03 , indicating small effect. As shown in Table 2, mean scores for gender and grade indicate that whereas reactive aggression increases markedly with grade in girls, boys show a much shallower developmental trajectory. With regard to the Proactive Aggression scores, results indicated a significant main effect for gender, $\mathrm{F}(1,373)=23.85, \mathrm{p}<.001$, with boys being more proactively aggressive than girls. The effect size $\left(\eta^{2}\right)$ was 0.06 , indicating small effect. A significant main effect for grade was also observed, $\mathrm{F}(2,373)=13.86, \mathrm{p}<.000$, with proactive aggression generally increasing with increasing grade. The effect size $\left(\eta^{2}\right)$ was 0.07 , indicating small effect. Using post hoc comparisons, sixth grade students had lower proactive aggression than seventh graders $(\mathrm{p}<.000)$, and eighth graders ( $\mathrm{p}<.000)$. The effect of Gender $\times$ Grade interaction was not statistically significant $\mathrm{F}(2,373)=$ $0.87, \mathrm{p}>.05$. See Table 2 for means and standard deviations. 
Uz Baş, A., \& Yurdabakan, İ. (2017). The relationship between reactive and proactive Aggression and emotional and behavioral difficulties: Criterion validity of the Reactive-Proactive Aggression Questionnaire (RPQ) among preadolescents. Journal of Human Sciences, 14(3), 2553-2564. doi:10.14687/jhs.v14i3.4494

Table 2. Means and Standard Deviations for Gender and Grade

\begin{tabular}{|c|c|c|c|c|c|}
\hline & Gender & Grade & $M$ & $S D$ & $n$ \\
\hline \multirow[t]{6}{*}{ Reactive Aggression } & Girls & 6 & 3.612 & 3.187 & 49 \\
\hline & & 7 & 7.943 & 3.346 & 71 \\
\hline & & 8 & 9.115 & 4.424 & 69 \\
\hline & Boys & 6 & 6.338 & 3.378 & 65 \\
\hline & & 7 & 7.701 & 4.338 & 67 \\
\hline & & 8 & 8.431 & 4.441 & 58 \\
\hline \multirow[t]{6}{*}{ Proactive Aggression } & Girls & 6 & 0.306 & 0.652 & 49 \\
\hline & & 7 & 1.225 & 1.465 & 71 \\
\hline & & 8 & 1.927 & 2.798 & 69 \\
\hline & Boys & 6 & 1.430 & 2.468 & 65 \\
\hline & & 7 & 2.611 & 2.801 & 67 \\
\hline & & 8 & 3.241 & 3.648 & 58 \\
\hline
\end{tabular}

\section{Correlation Analyses}

Pearson correlations between the RPAQ scores and the SDQ scores were calculated and presented in Table 3. As hypothesized, Reactive aggression was found to be significantly and positively correlated with emotional symptoms $(\mathrm{r}=.229, \mathrm{p}<.01)$, conduct problems $(\mathrm{r}=.386, \mathrm{p}$ $<.001)$, hyperactivity $(\mathrm{r}=.336, \mathrm{p}<.01)$, and peer problems $(\mathrm{r}=.122, \mathrm{p}<.05)$. Reactive aggression was also found to be significantly and negatively correlated with prococial behavior $(\mathrm{r}=$ $-.220, \mathrm{p}<.01)$. Similarly, Proactive aggression was found to be significantly and positively correlated with emotional symptoms $(\mathrm{r}=.161, \mathrm{p}<.01)$, conduct problems $(\mathrm{r}=.439, \mathrm{p}<.01)$, hyperactivity $(\mathrm{r}=.243, \mathrm{p}<.01)$, and peer problems $(\mathrm{r}=.111, \mathrm{p}<.05)$. Proactive aggression was also found to be significantly and negatively correlated with prococial behavior $(\mathrm{r}=-.323, \mathrm{p}<.01)$. The correlation between reactive and proactive aggression was also significant $(\mathrm{r}=.48, \mathrm{p}<.001)$.

Table 3. Correlations between the RPAQ and the SDQ scores

\begin{tabular}{lllllll}
\hline & $\begin{array}{l}\text { Emotional } \\
\text { symptoms }\end{array}$ & $\begin{array}{l}\text { Conduct } \\
\text { problems }\end{array}$ & Hyperactivity & Peer problems & $\begin{array}{l}\text { Prococial } \\
\text { behavior }\end{array}$ & $\begin{array}{l}\text { Total } \\
\text { difficulties }\end{array}$ \\
\hline $\begin{array}{l}\text { Reactive } \\
\text { aggression }\end{array}$ & $.229^{* * *}$ & $.386^{* * *}$ & $.336^{* * *}$ & $.122^{* *}$ & $-.220^{* * *}$ & $.383^{* * *}$ \\
$\begin{array}{l}\text { Proactive } \\
\text { aggression }\end{array}$ & $.161^{* *}$ & $.439^{* * *}$ & $.243^{* * *}$ & $.111^{*}$ & $-.323^{* * *}$ & $.332^{* * *}$ \\
$\begin{array}{l}\text { Total } \\
\text { aggression }\end{array}$ & $.233^{* * *}$ & $.468^{* * *}$ & $.346^{* * *}$ & $.136^{* *}$ & $-.299^{* * *}$ & $.418^{* * *}$
\end{tabular}

\footnotetext{
* correlation is significant at the 0.05 level (2-tailed)

** correlation is significant at the 0.01 level (2-tailed)

*** correlation is significant at the 0.001 level (2-tailed)
} 
Uz Baş, A., \& Yurdabakan, İ. (2017). The relationship between reactive and proactive Aggression and emotional and behavioral difficulties: Criterion validity of the Reactive-Proactive Aggression Questionnaire (RPQ) among preadolescents. Journal of Human Sciences, 14(3), 2553-2564. doi:10.14687/jhs.v14i3.4494

\section{Regression Analyses}

With regard to criterion validity of the RPQ, two separate stepwise regression analysis were used to determine whether emotional and behavioral difficulties and prosocial behavior were significant predictors of reactive and proactive aggression. Results of the regression analyses are presented in Table 4. Results regarding Reactive Aggression revealed that Conduct Problems $(\beta=$ $.295, \mathrm{p}<.001)$, Hyperactivity $(\beta=.178, \mathrm{p}<.01)$ and Emotional Symptoms $(\beta=.102, \mathrm{p}<.05)$ significantly and positively predicted Reactive Aggression scores. Conduct Problems, Hyperactivity and Emotional Symptoms, taken together, accounted for significant variation in Reactive Aggression scores $\left(\mathrm{R}^{2}=.197, \mathrm{p}<.001\right)$. Results regarding Proactive Aggression revealed that Conduct Problems $(\beta=.369, \mathrm{p}<.001)$ significantly and positively predicted Proactive Aggression scores, and Prosocial Behavior $(\beta=-.178, \mathrm{p}<.001)$ significantly and negatively predicted Proactive Aggression scores. Conduct Problems and Prosocial behavior, taken together, accounted for significant variation in Reactive Aggression scores $\left(\mathrm{R}^{2}=.219, \mathrm{p}<.001\right)$.

Table 4. Results of Stepwise Regression Analyses Predicting Reactive and Proactive Aggression

\begin{tabular}{|c|c|c|c|c|c|}
\hline Predicted Variable & Predictor Variable & B & SE & $B$ & $\mathrm{t}$ \\
\hline \multirow[t]{9}{*}{ Reactive Aggression } & (Constant) & 5.193 & 0.333 & - & 15.573 \\
\hline & Conduct Problems & 1.026 & 0.126 & 0.386 & $8.117 * * *$ \\
\hline & (Constant) & 3.884 & 0.448 & - & 8.673 \\
\hline & $\begin{array}{l}\text { Conduct Problems } \\
\text { Hyperactivity }\end{array}$ & 0.795 & 0.135 & 0.299 & $5.887^{* * *}$ \\
\hline & & 0.464 & 0.109 & 0.216 & $4.262^{* * *}$ \\
\hline & (Constant) & 3.659 & 0.460 & - & 7.959 \\
\hline & Conduct Problems & 0.784 & 0.135 & 0.295 & $5.829 * * *$ \\
\hline & Hyperactivity & 0.381 & 0.116 & 0.178 & $3.287^{* *}$ \\
\hline & Emotional Symptoms & 0.207 & 0.102 & 0.102 & $2.024^{*}$ \\
\hline \multirow[t]{5}{*}{ Proactive Aggression } & (Constant) & 0.277 & 0.204 & - & 1.354 \\
\hline & Conduct Problems & 0.735 & 0.077 & 0.439 & $9.484 * * *$ \\
\hline & (Constant) & 2.687 & 0.701 & - & 3.832 \\
\hline & Conduct Problems & 0.618 & 0.083 & 0.369 & $7.450 * * *$ \\
\hline & Prococial Behavior & -0.264 & 0.074 & -0.178 & $-3.589 * * *$ \\
\hline
\end{tabular}

${ }^{*} \mathrm{p}<.05 ;{ }^{* *} \mathrm{p}<.01 ; * * * \mathrm{p}<.001$

\section{Discussion}

The current study aimed to assess the criterion validity of the RPQ in a Turkish sample of school-going preadolescents. In accordance with this pupose, the relationship between two types of aggression, reactive and proactive aggression, and emotional and behavioral difficulties was investigated by Pearson correlations and multiple regression analysis.

The results of the correlation analysis revealed that, as expected, both reactive and proactive aggression were positively and significantly associated with conduct problems, emotional symptoms, hyperactivity and peer problems, while both aggression types were negatively and significantly associated with prosocial behavior. Further, reactive aggression was more strongly associated with emotional symptoms and hyperactivity than proactive aggression, whereas proactive 
Uz Baş, A., \& Yurdabakan, İ. (2017). The relationship between reactive and proactive Aggression and emotional and behavioral difficulties: Criterion validity of the Reactive-Proactive Aggression Questionnaire (RPQ) among preadolescents. Journal of Human Sciences, 14(3), 2553-2564. doi:10.14687/jhs.v14i3.4494

aggression was more strongly associated with conduct problems and prosocial behavior than reactive aggression. The strongest positive correlation was observed between conduct symptoms and proactive aggression. This is in line with previous empirical studies showing that proactive aggression is more strongly associated with delinquency and conduct disorder than reactive aggression (Fite et al., 2012; Raine et al., 2006; Vitaro et al., 1998). Scarpa, Haden and Tanaka (2010) found that reactive aggression was significantly related to increased internalizing behaviors and attention deficits, while proactive aggression was significantly related to increased hyperactivity/impulsivity and delinquent behavior problems. Furthermore, the current findings support previous research suggesting that reactive and proactive aggression are associated with distinct emotional and behavioral characteristics (Card \& Little, 2006; Polman et al., 2007). On the other hand, the weakest correlations were observed between peer problems and both reactive and proactive aggression. It seems that associations between peer problems and reactive and proactive aggression remain uncertain. Future research is needed to better understand the relationship between self-reported reactive and proactive aggression and peer problems among preadolescents. Results from stepwise regression analysis revealed that conduct problems were the strongest predictor of both reactive and proactive aggression. Besides conduct problems, emotional symptoms and hyperactivity were the significant predictors of reactive aggression (but not the proactive aggression). However, prosocial behavior was the significant predictor of proactive aggresion (but not the reactive aggression). In other words, reactive aggression was uniquely predicted by emotional symptoms and hyperactivity, and proactive aggression was uniquely predicted by prosocial behavior. Our findings support the notion that reactive aggression can lead to internalizing problems, whereas proactive aggression can lead to externalizing problems (Dodge et al., 1997; Colins, 2016; Pulkkinen,1996). Our findings are also in accordance with a recent work showing that only the proactive agrression was significantly negatively related to prosocial behavior (Colins, 2016). Overall, similar to past research with different samples, the results show that reactive and proactive aggression are distinct constructs. (Ang et al., 2016; Bozsik et al., 2013, Colins, 2016; Pechorro et al., 2016). Additionally, these findings support prior suggestions that reactively and proactively aggressive children and adolescents have different treatment needs (Colins, 2016).

In the current study, consistent with past research, the correlation between reactive and proactive aggression was significant, $\mathrm{r}=.48, \mathrm{p}<.001$, indicating that reactive and proactive aggression were related (Ang et al., 2016; Pechorro et al., 2016; Raine et al., 2006). However, proactive aggression scores were considerably lower than reactive aggression scores. The same findings have been observed in previous studies using the RPQ (Bozsik et al., 2013; Fung et al., 2009; Raine et al., 2006). Consistent with the early findings, the results of the current study imply that reactive aggression is more normative in this Turkish school-aged children sample (Uz Baş \& Yurdabakan, 2012).

Analysis of gender and grade differences revealed that boys get higher scores on both Reactive and Proactive Aggression scales. These findings were consistent with previous findings implying higher rates of both reactive and proactive aggression for boys compared to girls (Salmivalli \& Nieminen, 2002; Uz Baş \& Yurdabakan, 2012). Regarding grade level differences, consistent with the past research, findings showed a linear increase in both aggression scores from Grade 6 to Grade 8 (Fung et al., 2009; Uz Baş \& Yurdabakan, 2012). The increase in reactive aggression, especially for girls, between Grade 6 and Grade 8 is remarkable. These findings point to distinct developmental trajectories for reactive and proactive aggression.

Although our results have contributed to the current knowledge regarding reactive and proactive aggression among preadolescents, some limitations should be considered. First, our results were cross-sectional in nature and limit conclusions. Thus, future researchers should use longitudinal study design in order to assess associations over time. Second, this study used selfreport measures in order to assess the associations between reactive and proactive aggression and emotional and behavioral difficulties. Thus, future research should use alternative sources of 
Uz Baş, A., \& Yurdabakan, İ. (2017). The relationship between reactive and proactive Aggression and emotional and behavioral difficulties: Criterion validity of the Reactive-Proactive Aggression Questionnaire (RPQ) among preadolescents. Journal of Human Sciences, 14(3), 2553-2564. doi:10.14687/jhs.v14i3.4494

information including peer nominations or parent reports. Finally, evidence demonstrating criterion validity of the RPQ scores were limited to the SDQ scores. It would be preferable to have had a wider range of other measures included.

\section{Conclusions and recommendations}

In conclusion, criterion validity of the RPQ was confirmed by significant correlations between the RPQ scores and the SDQ scores, and the distinctive predictive roles of the SDQ subscores in reactive and proactive aggression scores among Turkish preadolescents. The findings of the present study have some implications for school counselors. This study shows that the RPQ is able to identify two types of aggressive behavior among school-going preadolescents. Thus, it would be a useful measure for school counselors who are responsible for preventing and intervening aggression in school environments.

The findings of the present study revealed that reactive and proactive aggression are associated with distinct emotional and behavioral characteristics. These findings have some implications for intervention efforts. Research indicated that reactive and proactive aggression each require unique prevention and intervention methods (Brown \& Parsons, 1998). Treatment effectiveness has been directly related to the use of subtype-specific treatment protocol with aggressive children and adolescents (McAdams, 2002). For example, McAuliffe, Hubbard, Rubin, Morrow, \& Dearing (2007) suggested that interventions aim at reactive aggression would emphasize anger management, peer relations and social skills training, hostile attributional bias reduction, social problem solving and reductions in internalizing symptoms. Conversely, treatment for proactive aggression would stress development of empathy, negative consequences of aggressive behavior and importance of social goals. Due to these reasons, school counselors and the other mental health professionals should take into consideration different natures of two types of aggression in their intervention efforts.

Our results also highlighted gender and grade level differences in reactive and proactive aggression. Thus, school counselors who aim to intervene effectively in reactive and proactive aggression should address differentiating needs of preadolescent boys and girls.

\section{References}

Anderson, C. A., \& Bushman, B. J. (2002). Human aggression. Annual Review of Psychology, 53, 27-51.

Ang, R. P., Huan, V. S., Li, X., \& Chan, W. T. (2016). Factor Structure and Invariance of the Reactive and Proactive Aggression Questionnaire in a Large Sample of Young Adolescents in Singapore. Child Psychiatry \& Human Development, 47(6), 883-889.

Berkowitz, L. (1989). Frustration-aggression hypothesis: Examination and reformulation. Psychological Bulletin, 106, 59-73.

Bozsik, C., Körmendi, A., Inántsy-Pap, J., Pataky, N., Gádoros, J., \& Halász, J. (2013). The relationship between reactive/proactive aggression, callous/unemotional traits and behavioural problems in Hungarian adolescents. Psychiatr Hung, 28(1), 48-56.

Brendgen, M., Vitaro, F., Tremblay, R. E., \& Lavoie, F. (2001). Reactive and proactive aggression: Predictions to physical violence in different contexts and moderating effects of parental monitoring and care-giving behavior. Journal of Abnormal Child Psychology, 29, 293-304.

Brown, K., Atkins, M. S., Osborne, M. L., \& Milmanow, M. (1996). A revised teacher-rating scale for reactive and proactive aggression. Journal of Abnormal Child Psychology, 24, 473-480.

Brown, K. S., \& Parsons, R. D. (1998). Accurate identification of childhood aggression: A key to successful intervention. Professional School Counseling, 2(2), 135-140. 
Uz Baş, A., \& Yurdabakan, İ. (2017). The relationship between reactive and proactive Aggression and emotional and behavioral difficulties: Criterion validity of the Reactive-Proactive Aggression Questionnaire (RPQ) among preadolescents. Journal of Human Sciences, 14(3), 2553-2564. doi:10.14687/jhs.v14i3.4494

Card, N. A. (2013). Peer Aggression: Research Brief. (Ed. Debbie Casper, Bryna Koch, Lynne M. Borden). Norton School of Family and Consumer Sciences Cooperative Extension, Arizona. Retrieved January 14, 2016, from http://reachmilitaryfamilies.arizona.edu

Card, N. A., \& Little, T. D. (2004). Proactive and reactive aggression in childhood and adolescence. A meta-analysis of differential relations with psychosocial adjustment. International Journal of Behavioral Development, 30, 466-80.

Cohen, L., Manion, L., \& Morrison, K. (2007). Research methods in education (6th ed.). New York, NY: Routledge.

Colins, O. F. (2016). Assessing reactive and proactive aggression in detained adolescents outside of a research context. Child Psychiatry \& Human Development, 47, 159-172.

Crick, N. R., \& Dodge, K. A. (1996). Social information processing mechanisms in reactive and proactive aggression. Child Development, 67, 993-1002.

Day, D. M., Bream, L. A., \& Paul, A. (1992). Proactive and reactive aggression: An analysis of subtypes based on teacher perceptions. Journal of Clinical Child Psychology, 21, 210-217.

Dodge, K. A., \& Coie, J. D. (1987). Social-information processing factors in reactive and proactive aggression in children's peer groups. Journal of Personality and Social Psychology, 53, 11461158.

Dodge, K. A., Lochman, J. E., Harnish, J. D., Bates, J. E., \& Pettit, G. S. (1997). Reactive and proactive aggression in school children and psychiatrically impaired chronically assaultive youth. Journal of Abnormal Psychology, 106, 37-51.

Dursun, O.B., Güvenir, T. \& Özbek, A. (2010). Epidemiologic Studies in Child and Adolescent Psychiatry: A Review of Methodology. Current Approaches in Psychiatry, 2, 3, 401-416.

Euler, F., Steinlin, C. \& Stadler, C. (2017). Distinct profiles of reactive and proactive aggression in adolescents: associations with cognitive and affective empathy. Child and Adolescent Psychiatry and Mental Health, 11, 1.

Fite, P.J., Wimsatt, A.R., Elkins, S., \& Grasetti, S.N. (2012). Contextual influences of proactive and reactive subtypes of aggression. Child Indicators Research, 5, 123-133.

Fossati, A., Raine, A., Borroni, S., Bizzozero, A., Volpi, E., Santalucia, I., \& Maffei, C. (2009). A crosscultural study of the psychometric properties of the Reactive-Proactive Aggression Questionnaire among Italian non-clinical adolescents. Psychological Assessment, 11, 131135.

Fung, A. L., Raine, A., \& Gao, Y. (2009). Cross-cultural generalizability of the Reactive-Proactive Aggression Questionnaire (RPQ). Journal of Personality Assessment, 91(5), 473-479.

Goodman, A. \& Goodman, R (2009). Strengths and Difficulties Questionnaire as a Dimensional Measure of Child Mental Health. Journal of the American Academy of Child and Adolescent Psychiatry, 48(4). pp. 400-3. ISSN 0890-8567

Güvenir T, Ozbek A, Baykara B, Arkar H, Şentürk B, \& Incekaş S. (2008). Psychometric Properties of The Turkish Version of The Strengths and Difficulties Questionnaire (SDQ). Turkish Child and Adolescent Mental Health, 15(2), 65-74.

Hubbard, J. A., Dodge, K. A., Cillessen, A. H. N., Coie, J. D., \& Schwartz, D. (2001). The dyadic nature of social information processing in boys' reactive and proactive aggression. Journal of Personality and Social Psychology, 80(2), 268-280.

Hubbard, J. A., Smithmyer, C. M., Ramsden, S. R., Parker, E. H., Flanagan, K. D., Dearing, K. F., . . . Simons, R. F. (2002). Observational, physiological, and self-report measures of children's anger: Relations to reactive versus proactive aggression. Child Development, 73(4), 1101 1118.

Kempes, M., Matthys, W., de Vries, H., \& van Engeland, H. (2005). Reactive and proactive aggression in children: A review of theory, findings and the relevance for child and adolescent psychiatry. European Child \& Adolescent Psychiatry, 14, 11-19. 
Uz Baş, A., \& Yurdabakan, İ. (2017). The relationship between reactive and proactive Aggression and emotional and behavioral difficulties: Criterion validity of the Reactive-Proactive Aggression Questionnaire (RPQ) among preadolescents. Journal of Human Sciences, 14(3), 2553-2564. doi:10.14687/jhs.v14i3.4494

McAdams, C. R. (2002). Trends in the occurrence of reactive and proactive aggression among children and adolescents: Implications for preparation and practice in child and youth care. Child \& Youth Care Forum, 31(2), 89-109.

McAuliffe, M. D., Hubbard, J. A., Rubin, R. M., Morrow, M. T., \& Dearing, K. F. (2007). Reactive and Proactive Aggression: Stability of constructs and relations to correlates. The Journal of Genetic Psychology, 167(4), 365-382.

Pechorro, P., Ray, J. V., Raine, A., Maroco, J. \& Gonçalves, R. A. (2015). The Reactive-Proactive Aggression Questionnaire: Validation Among a Portuguese Sample of Incarcerated Juvenile Delinquents, Journal of Interpersonal Violence, 1-23.

Polman, H. (2008). Hot-Headed or Cold-Blooded? Towards a Clear Distinction between Reactive and Proactive Aggression in Youth. Unpublished master's thesis. Utrecth University, Netherlands. Retrieved July 20, 2014, from http://dspace.library.uu.nl/handle/1874/27772

Poulin, F., \& Boivin, M. (2000). Reactive and proactive aggression: Evidence of a two-factor model. Psychological Assessment, 12(2), 115-122.

Pulkkinen, L. (1996). Proactive and reactive aggression in early adolescence as precursors to antiand prosocial behaviors in young adults. Aggressive Behavior, 22, 241-257.

Raine, A., Dodge, K. A., Loeber, R., Gatzke-Kopp, L., Lynam, D., Reynolds, C., et al. (2006). The reactive-proactive questionnaire: differential correlates of reactive and proactive aggression in adolescent boys. Aggressive Behavior, 32, 159-171.

Rathert, Jamie Lee, "Influence of Parenting Behavior on Behavioral and Psychological Associations of Proactive and Reactive Aggression." Master's Thesis, University of Tennessee, 2009. http://trace.tennessee.edu/utk_gradthes/552

Salmivalli, C., \& Nieminen, E. (2002). Proactive and reactive aggression among school bullies, victims, and bully-victims. Aggressive Behavior, 28, 30-44.

Scarpa, A., Haden, S. C., \& Tanaka, A. (2010). Being hot-tempered: Autonomic, emotional, and behavioral distinctions between childhood reactive and proactive aggression. Biological Psychology 84, 488-496.

Uz Baş, A. \& Yurdabakan, İ. (2012). Factor Structure of the Reactive-Proactive Aggression Questionnaire in Turkish Children and Gender, Grade-Level, and Socioeconomic Status Differences in Reactive and Proactive Aggression. Journal of Psychoeducational Assessment, 30(3), 284-297.

Vitaro, F., Brendgen, M., \& Barker, E.D. (2006). Subtypes of aggressive behaviors: A developmental perspective. International Journal of Behavioral Development, 30, 12-19.

Vitaro, F., Gendreau, P. L., Tremblay, R. E., \& Oligny, P. (1998). Reactive and proactive aggression differentially predict later conduct problems. Journal of Clinical Child Psychology and Psychiatry, 39, 377-385. 